\title{
Cognitive markers of short-term clinical outcome in first-episode psychosis
}

\author{
Michael Bodnar, Ashok Malla, Ridha Joober and Martin Lepage
}

\section{Background}

Outcome from psychotic disorders is heterogeneous with poorer outcomes frequently identified too late to be influenced. Symptomatic ratings at 1 or more years following initiation of treatment have been related to cognition in firstepisode psychosis. However, the relationship between cognition and early outcome remains unclear.

\section{Aims \\ To determine whether specific cognitive domains could identify poor short-term outcome among individuals with first-episode psychosis.}

\section{Method}

One hundred and fifty-one individuals with first-episode psychosis were divided into two groups based on 6-month clinical data after the initiation of treatment. Six cognitive domains were compared among 78 participants with poor outcomes, 73 with good outcomes and 31 healthy controls.

\section{Results}

Lower performance on verbal memory (z-scores: poor outcome $=-1.3$ (s.d.=1.1); good outcome $=-0.8$ (s.d.=0.9); $P=0.001$ ) and working memory (poor outcome $=-1.0$ (s.d.=1.2); good outcome $=-0.4$ (s.d. $=0.9$ ); $P=0.003$ ) identified individuals with first-episode psychosis with a poor outcome after 6 months of treatment.

\section{Conclusions}

The early identification of those individuals with first-episode psychosis with a poor clinical outcome may encourage clinicians to pay special attention to them in the form of alternative pharmacological and psychological treatments for a more favourable outcome in the long term.

\section{Declaration of interest}

None. Funding detailed in Acknowledgements.
Substantial proportions of people with first-episode psychosis respond poorly to or do not respond to treatment. ${ }^{1,2}$ Cognitive deficits, frequently present in first-episode psychosis, ${ }^{3-5}$ have been related to poor functional outcome $e^{6,7}$ as well as higher symptomatic levels at 1 or more years after the initiation of treatment. ${ }^{8,9}$ However, the relationship between short-term clinical outcome and different cognitive domains has not been studied in first-episode psychosis. In this study, we compared cognitive profiles to determine: first, whether specific cognitive deficits could differentiate between outcomes in a specialised treatment programme for first-episode psychosis, and second, the differential profile of cognitive performances among those with good outcomes, poor outcomes, and in healthy controls.

\section{Method}

\section{Participants, treatment setting and treatment protocol}

All participants were part of a longitudinal naturalistic outcome study of first-episode psychosis treated in a specialised early intervention service: the Prevention and Early Intervention Program for Psychoses (PEPP-Montreal), Douglas Mental Health University Institute in Montreal, Canada. The PEPP-Montreal is a specialised early intervention service with integrated clinical, research and teaching modules. The programme involves a comprehensive approach with intensive medical and psychosocial management provided primarily through modified case management. Pharmacotherapy begins with a second-generation antipsychotic medication (olanzapine, risperidone or quetiapine) within the recommended doses for a period of 4-6 weeks followed by an assessment of therapeutic response. In case therapeutic response is not optimal or side-effects are noticed, an alternate second-generation antipsychotic medication is prescribed. Although specific treatment for psychosis begins with the initiation of antipsychotic medication, people who initially refuse drug therapy, as well as their families, are still provided with case management, support and education. This may extend for weeks and, occasionally, several months. In addition, they all have modified assertive case management and interventions to assist in their social recovery (see Malla et $a l^{10}$ for more details). Individuals aged 14-30 years from the local catchment area with either affective or non-affective psychosis who have not taken antipsychotic medication for more than 1 month were consecutively admitted to the programme as either in- or out-patients. There is no competing service and treatment is publicly funded.

The PEPP-Montreal provided treatment to 233 people with first-episode psychosis between 9 January 2003 and 6 March 2008. Of these, 166 individuals had received treatment for a minimum of 6 months and completed a neuropsychological evaluation. Of the 166 individuals in the study, 15 were subsequently removed from the analysis due to either neuropsychological testing conducted beyond 6 months $(n=12)$ or a confirmed diagnosis of substance-induced psychosis $(n=3)$. Those who were included were separated into good-outcome $(n=73)$ and pooroutcome $(n=78)$ groups based on 6-month clinical data. Good outcome was defined with a rating of 2 or less (mild) on all global sub-scales of the Scale for the Assessment of Positive Symptoms $(\mathrm{SAPS})^{11}$ and 3 or less (moderate) on all global sub-scales except 'attention' of the Scale for the Assessment of Negative Symptoms (SANS). ${ }^{12}$ Further comparisons between the removed individuals $(n=15)$ and the included individuals $(n=151)$ indicated no differences on any of the socio-demographic, clinical or cognitive variables.

Thirty-one healthy controls were recruited through advertisements placed in local newspapers. Controls were included only if they had no current or past history of any Axis I disorders; any neurological diseases; head trauma causing loss of consciousness; or a first-degree family member suffering from schizophrenia or 
related schizophrenia-spectrum psychosis. Controls were also chosen based on such socio-demographic variables as age at the time of neuropsychological testing, gender and parental socioeconomic status that were separately matched to a subset of the current sample of participants with first-episode psychosis who were also taking part in a neuroimaging study.

After a comprehensive description of the study, written informed consent was obtained from all participants. Research protocols were approved by the Douglas Hospital human ethics review board.

\section{Clinical and demographic assessments}

People were diagnosed according to the DSM-IV criteria based on the Structured Clinical Interview for DSM-IV. ${ }^{13}$ Positive and negative symptoms were assessed with the SAPS and the SANS respectively. The baseline interview session was conducted within 1 month of entry into the programme (mean $=22.6$ days, s.d. $=8.5$, range $=4.8-49.2$ ). The symptom ratings were repeated at 1 month, 2 months, 3 months and 6 months past baseline.

Medication adherence was measured at each of the aforementioned time-points using a five-point scale ranging from 0 (never adherent) to 4 (fully adherent) based on composite information obtained from participants, family members, case managers and psychiatrists. ${ }^{14}$ These ratings were averaged over the 6-month period to provide an overall mean score for adherence. Duration of untreated psychosis (DUP) was calculated as the time period from onset of psychotic symptoms to adequate treatment with antipsychotics, while duration of untreated illness (DUI) was defined as the time period from onset of any psychiatric symptoms to adequate treatment with antipsychotics. ${ }^{14}$ At baseline, DUP and DUI were calculated based on these definitions, in addition to premorbid functioning levels with the Premorbid Adjustment Scale (PAS) ${ }^{15}$ and parental socio-economic status according to the Hollingshead two-factor index of social position. ${ }^{16}$ All ratings were conducted by trained research staff who had participated in regular interrater reliability sessions and were not directly involved in the participants treatment. All interviews and rating sessions were confirmed via consensus between two senior research psychiatrists (A.M. and R.J.). Finally, the type and dosage of antipsychotic taken at the time of the neuropsychological evaluation were recorded.

\section{Cognitive assessment}

A standardised cognitive battery was completed by all participants; tested and scored by a trained professional who was not involved with the treatment of the individuals. Participants were assessed after the initiation of treatment and only when in a stable but not necessarily asymptomatic condition. There was no difference between groups with respect to when evaluations took place following entry into the programme (poor outcome: mean $=7.2$ weeks, s.d. $=5.2$; good outcome: mean $=8.8$ weeks, s.d. $=7.2$; $t=-1.58$, d.f. $=149, P=0.12$ ). Cognitive ability was examined by separating various neuropsychological tests into six cognitive domains as suggested by the NIMH-Measurement and Treatment Research to Improve Cognition in Schizophrenia (MATRICS) group. ${ }^{17,18}$ The following domains were derived: Verbal Learning and Memory from the Logical Memory sub-tests of the Wechsler Memory Scale - third edition (WMS-III); ${ }^{19}$ Visual Learning and Memory from the Visual Reproduction sub-tests of the WMS-III; Working Memory from the Spatial Span sub-tests of the WMS-III and the Digit Span sub-tests of the Wechsler Adult Intelligence Scale - third edition (WAIS-III); ${ }^{20}$ Speed of Processing from the Trail Making Test A (completion time) ${ }^{21}$ and the Digit Symbol sub-test of the WAIS-III; Reasoning/Problem-Solving from the
Trail Making Test B (completion time) and the Block Design subtest of the WAIS-III; and Attention from the d2 Test of Attention (concentration performance score). ${ }^{22}$

\section{Statistical analysis}

All clinical characteristics were normally distributed (ShapiroWilks $W$-test) except for DUP and DUI, which were normalised using logarithmic and square root transformations respectively. A one-way analysis of variance (ANOVA) was used to examine age at neuropsychological testing among the three groups. Independent $t$-tests were used to compare baseline and 6-month total symptom ratings, changes in symptom scores, dosage of antipsychotic medication, medication adherence, DUP, DUI and PAS scores between the patient outcome groups. Parental socioeconomic status among the three groups was contrasted using a Kruskall-Wallis one-way ANOVA. Gender and type of antipsychotic were compared using cross-tabulation and chi-squared tests.

Seven neuropsychological variables required square-root transformations, while two required logarithmic transformations to achieve normal distribution. All neuropsychological variables, including IQ scores (WAIS-III) were then transformed into standard equivalents ( $z$-scores) using the mean and standard deviation of the healthy control group. Cognitive domains were calculated by averaging the $z$-scores of the pertinent sub-tests and then normalised using the mean and standard deviation of the healthy control group. Lastly, an overall cognitive performance score for each group was calculated by averaging the six cognitive domains.

A within-patient repeated-measure multivariate analysis of variance (MANOVA) was used to compare the profile of cognitive performance among the groups, using group membership (poor outcome, good outcome and control) as the between-groups factor and the cognitive domains as the within-group factors. Univariate ANOVAs with post hoc Bonferroni pairwise contrasts were used to identify group differences where necessary. The critical $P$-value was set to 0.008 following the Bonferroni correction procedure to control for multiple comparisons. One-way ANOVAs with post hoc Bonferroni comparisons were used to compare the IQ measures and overall cognitive performance score among the three groups. In addition, one-way ANOVAs were used to examine the cognitive profiles and IQ measures among the individuals with first-episode of schizophrenia and those in the non-first-episode psychosis sample. Independent $t$-tests between these two groups were then used to compare the cognitive domains and IQ measures within each outcome group. Finally, for the entire sample, Pearson's chi-squared and Spearman's rho ( $\rho$ ) examined the independence and correlations, respectively, between the cognitive domains and symptom levels at the time of the neuropsychological evaluation. Additionally, cross tabulation and chi-squared tests were used to examine if there was an effect of the heterogeneous sample on the cognitive profile. All statistical tests were two-tailed with the critical $P$-value set at 0.05 , except for the MANOVA as previously noted, and performed using SPSS version 12 for Windows.

\section{Results}

\section{Clinical and demographic data}

Individuals were diagnosed with schizophrenia-spectrum disorder $(n=110(73 \%)$; poor outcome $=64$; good outcome $=46)$, affective psychosis $(n=24(16 \%)$; poor outcome $=8$; good outcome $=16)$, and psychosis not otherwise specified/delusional disorder $(n=17$ $(11 \%)$; poor outcome $=6$; good outcome $=11)$. The poor-outcome, 
good-outcome and control groups did not differ with respect to age, gender or parental socio-economic status (Table 1). Further, the poor-outcome and good-outcome groups did not differ in DUP, DUI and medication adherence. With respect to medication adherence, two patients with a poor outcome and four with a good outcome refused antipsychotic treatment during the 6 months but still received psychosocial treatment from the PEPP (Table 2). There was no difference in the type of antipsychotic medication taken at the time of neuropsychological testing; however, patients in the poor-outcome group taking olanzapine (but not any other antipsychotics) received significantly higher doses compared with the good-outcome group. There was no premorbid educational difference between the groups with firstepisode psychosis as indicated by the PAS; however, the pooroutcome group had a lower level (higher score) of premorbid social adjustment during childhood and early adolescence (Table 2). Finally, at baseline, positive symptoms were equivalent among patients but negative symptoms were significantly higher in the poor-outcome group, while at 6 months, the good-outcome group were significantly lower in both positive and negative symptoms, as per design. Over the 6-month period, improvements in positive and negative symptoms were significantly better for the goodoutcome group (Table 2).

\section{Neurocognitive data}

The cognitive profiles in the three groups were not parallel as indicated by a significant (group cognitive domain) interaction $(F=6.27$, d.f. $=12,348, P<0.001)$ in the analysis involving the entire first-episode psychosis sample with healthy controls (Fig. 1). Subsequent univariate ANOVAs revealed mean differences among the groups in all cognitive domains. Post hoc comparisons indicated the poor-outcome group functioned at levels significantly below the good-outcome group in both working memory and verbal learning and memory. Moreover, compared with the healthy controls, the poor-outcome group displayed significant deficits in all cognitive domains; the goodoutcome group also displayed significant deficits in all domains except in working memory (Table 3 ).

A one-way ANOVA indicated significant differences among the three groups for overall cognitive performance $(F=23.24$, d.f. $=2,179, P<0.001)$. Post hoc analyses revealed that patients in

\begin{tabular}{|c|c|c|c|c|c|c|}
\hline & \multirow[b]{2}{*}{ Poor outcome $(N=78)$} & \multirow[b]{2}{*}{ Good outcome $(N=73)$} & \multirow[b]{2}{*}{ Control $(N=31)$} & \multicolumn{3}{|c|}{ Analysis } \\
\hline & & & & Statistic & d.f. & $P$ \\
\hline Age, years: mean (s.d.) & $23.0(3.8)$ & $22.9(4.1)$ & $24.7(3.3)$ & $F=2.38$ & 2,179 & 0.10 \\
\hline Parental SES score, ${ }^{a}$ mean (s.d.) $[n]$ & $3.1(1.1)[57]$ & $2.7(0.9)[56]$ & $3.0(0.9)$ & $\chi^{2}=5.57$ & 2 & 0.06 \\
\hline Gender, M/F & $55 / 23$ & $49 / 24$ & $17 / 14$ & $\chi^{2}=2.47$ & 2 & 0.29 \\
\hline
\end{tabular}

\begin{tabular}{|c|c|c|c|c|c|}
\hline & \multirow[b]{2}{*}{ Poor outcome $(\mathrm{N}=78)$} & \multirow[b]{2}{*}{ Good outcome $(N=73)$} & \multicolumn{3}{|c|}{ Analysis } \\
\hline & & & Statistic & d.f. & $P$ \\
\hline DUP, weeks: ${ }^{a}$ mean (s.d.) median [ $\left.n\right]$ & $44.5(76.1) 18.6[70]$ & $49.3(95.9) 14.1[65]$ & $t=0.45$ & 133 & 0.651 \\
\hline DUI, weeks: ${ }^{a}$ mean (s.d.) median [n] & $272.8(244.4) 180.9$ [70] & $245.3(261.9) 163.7$ [65] & $t=0.90$ & 133 & 0.371 \\
\hline \multicolumn{6}{|l|}{ PAS, mean (s.d.) $[n]$} \\
\hline Childhood & $0.23(0.14)[55]$ & $0.17(0.13)[60]$ & $t=2.15$ & 113 & $0.03^{*}$ \\
\hline Early adolescence & $0.29(0.16)[55]$ & $0.24(0.14)[59]$ & $t=2.13$ & 112 & $0.04^{*}$ \\
\hline Social & $0.27(0.21)[47]$ & $0.17(0.16)[51]$ & $t=2.65$ & 96 & $0.01 *$ \\
\hline Educational & $0.32(0.19)[42]$ & $0.29(0.17)[50]$ & $T=0.78$ & 90 & 0.44 \\
\hline \multicolumn{2}{|l|}{ Antipsychotic, mg/day: mean (s.d.) [n] } & & $\chi^{2}=8.70$ & 6 & 0.19 \\
\hline Olanzapine & $11.9(6.2)[32]$ & $8.7(4.4)$ [39] & $t=2.57$ & 69 & $0.01 *$ \\
\hline Risperidone & $2.1(1.1)[30]$ & $2.0(1.2)[17]$ & $t=0.24$ & 45 & 0.82 \\
\hline Quetiapine & 314.3 (121.5) [7] & $402.1(243.5)[6]$ & $t=-0.84$ & 11 & 0.42 \\
\hline Risperidone injected & 31.3 (12.5) [4] & $25.0[1]$ & $t=0.45$ & 3 & 0.69 \\
\hline Haloperidol & [0] & $2.0[1]$ & n/a & & \\
\hline Loxapine & [0] & $75.0[1]$ & $\mathrm{n} / \mathrm{a}$ & & \\
\hline None & {$[5]$} & [8] & $\mathrm{n} / \mathrm{a}$ & & \\
\hline Medication adherence:b mean (s.d.) & $3.2(1.1)$ & $3.3(1.1)$ & $t=-0.35$ & 149 & 0.73 \\
\hline \multicolumn{6}{|l|}{ SAPS total: mean (s.d.) } \\
\hline Baseline & $32.0(14.7)$ & $29.3(14.0)$ & $t=1.13$ & 149 & 0.26 \\
\hline 6-month & $13.2(13.3)$ & $2.1(3.3)$ & $t=6.87$ & 149 & $<0.001 *$ \\
\hline Change & $18.8(15.2)$ & $27.2(14.0)$ & $t=-3.53$ & 149 & $0.001 *$ \\
\hline \multicolumn{6}{|l|}{ SANS total: mean (s.d.) } \\
\hline Baseline & 30.1 (14.4) & $22.0(13.7)$ & $t=3.52$ & 149 & $0.001 *$ \\
\hline 6-month & 27.9 (13.3) & $12.7(11.7)$ & $t=7.46$ & 149 & $<0.001^{*}$ \\
\hline Change & $2.1(13.1)$ & $9.3(13.6)$ & $t=-3.29$ & 149 & $0.001^{*}$ \\
\hline \multicolumn{6}{|c|}{$\begin{array}{l}\text { n, number of participants for whom data are presented.; DUP, duration of untreated psychosis; DUI, duration of untreated illness; PAS, Premorbid Adjustment Scale; } \\
\text { SAPS, Scale for the Assessment of Positive Symptoms; SANS, Scale for the Assessment of Negative Symptoms. } \\
\text { *Significant at } P<0.05 \text { level. } \\
\text { a. DUP and DUI are presented in raw form; however, these were analysed using transformed data. } \\
\text { b. Medication adherence average over } 6 \text { months: } 0 \text { (never adherent) to } 4 \text { (always adherent); two individuals from the poor-outcome group and four from the good-outcome group } \\
\text { refused antipsychotic treatment but still received psychosocial interventions. }\end{array}$} \\
\hline
\end{tabular}


the poor-outcome group (mean $z$-score $=-1.3$, s.d.=1.1) functioned significantly below both the good-outcome (mean $z$-score $=-0.9$, s.d. $=0.8)(P=0.02)$ group and healthy controls (mean=0.0, s.d.=1.0) $(P<0.01)$; the good-outcome group also functioned significantly below the healthy controls $(P<0.01)$. In addition, a one-way ANOVA revealed differences in Verbal IQ, Performance IQ, and Full-scale IQ among the three groups. Post hoc analyses indicated the group with poor outcomes had a lower score than the group with a good outcome on only the verbal measure. Compared with healthy controls, the poor-outcome group were compromised on all three measures, while the good-outcome group were compromised in both the performance and full-scale measures (Table 3).

The means and standard deviations along with all statistical results are reported in Table 3 for the entire first-episode psychosis sample, and in online Table DS1 for the entire sample, the firstepisode schizophrenia and the non-first-episode schizophrenia subgroups. The raw data are available in online Table DS2. As expected, the supplementary ANOVAs for the first-episode schizophrenia and non-first-episode schizophrenia subgroups revealed significant differences in all cognitive domains among the poor-outcome, good-outcome, and healthy control groups. Of importance, working memory and verbal memory were significantly compromised in the poor-outcome groups compared with the good-outcome groups for both the first-episode schizophrenia and non-first-episode schizophrenia patients. In addition, compared with healthy controls, the poor-outcome groups had significant deficits in all cognitive domains, while the goodoutcome groups had varying results among the first-episode schizophrenia and non-first-episode schizophrenia patients. The

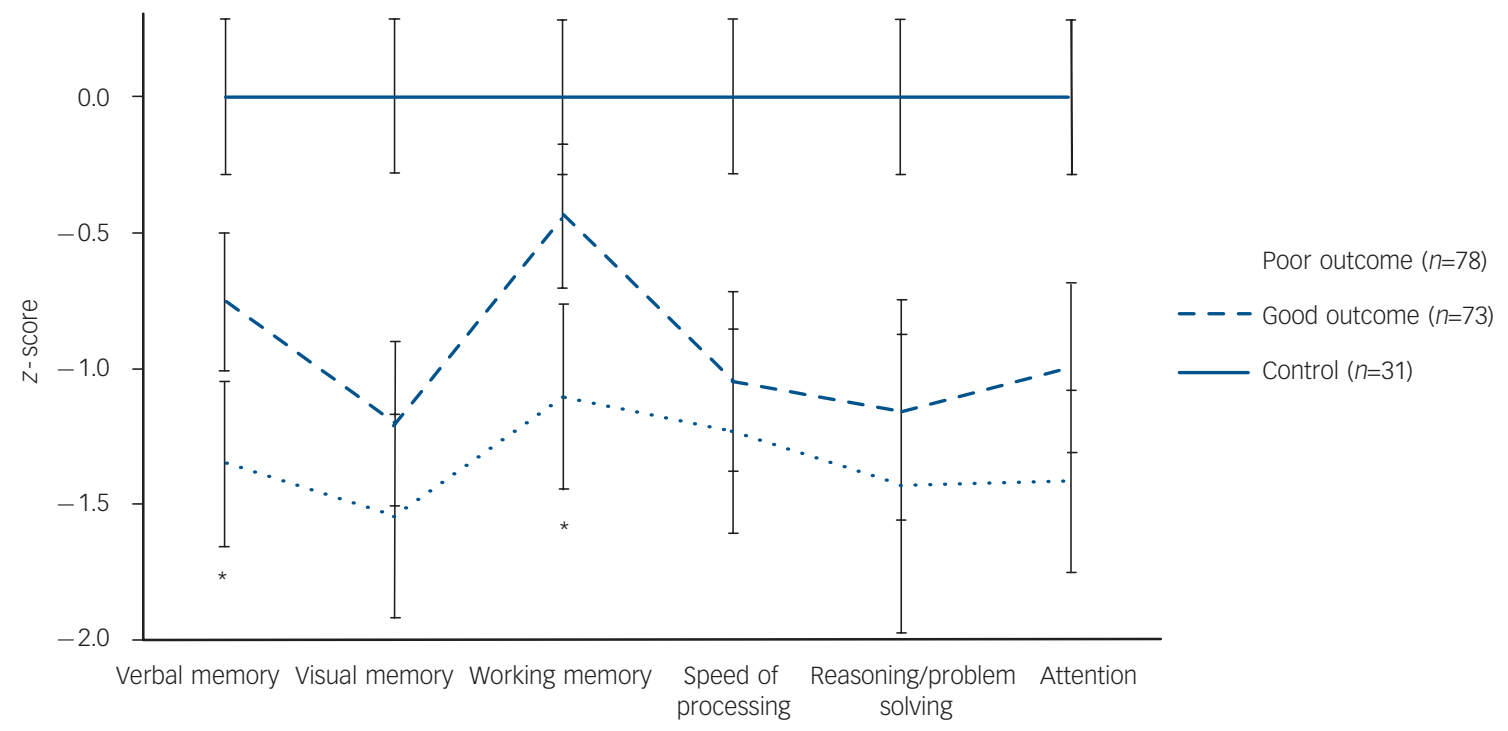

Fig. 1 Neurocognitive profile of poor-outcome, good-outcome and healthy control groups. The poor-outcome group performed significantly below the good-outcome group in only the verbal memory and working memory domains; no significant differences were found for the other domains. In general, the poor-outcome and good-outcome groups functioned at lower levels compared with the control group with the poor-outcome group at a more severe level.

\begin{tabular}{|c|c|c|c|c|c|c|c|}
\hline & \multirow[b]{2}{*}{ Poor outcome ${ }^{b}$} & \multirow[b]{2}{*}{ Good outcome } & \multicolumn{5}{|c|}{ Analysis } \\
\hline & & & $F^{\mathrm{c}}$ & $P$ & Good v. poor & Good v. control & Poor v. control \\
\hline \multicolumn{8}{|l|}{ Cognitive domains ${ }^{d}$} \\
\hline Verbal learning and memory & $-1.3(1.1)$ & $-0.8(0.9)$ & 21.60 & $<0.001$ & $0.001 * *$ & $0.001 * *$ & $<0.001 * *$ \\
\hline Visual learning and memory & $-1.5(1.3)$ & $-1.2(1.1)$ & 19.50 & $<0.001$ & 0.229 & $<0.001 * *$ & $<0.001 * *$ \\
\hline Working memory & $-1.0(1.2)$ & $-0.4(0.9)$ & 17.40 & $<0.001$ & $0.003^{* *}$ & 0.171 & $<0.001 * *$ \\
\hline Speed of processing & $-1.2(1.3)$ & $-1.0(1.2)$ & 11.98 & $<0.001$ & 1.000 & $<0.001^{* *}$ & $<0.001^{* *}$ \\
\hline Reasoning/problem-solving & $-1.4(1.9)$ & $-1.2(1.4)$ & 8.95 & $<0.001$ & 0.909 & $0.003^{* *}$ & $<0.001^{* *}$ \\
\hline Attention & $-1.4(1.2)$ & $-1.0(1.1)$ & 17.82 & $<0.001$ & 0.067 & $<0.001 * *$ & $<0.001 * *$ \\
\hline \multicolumn{8}{|l|}{ WAIS-III IQ measures ${ }^{\mathrm{e}}$} \\
\hline Verbal & $-0.9(1.0)$ & $-0.5(1.0)$ & 9.46 & $<0.01$ & $0.03^{*}$ & 0.09 & $<0.01 *$ \\
\hline Performance & $-1.5(1.8)$ & $-1.2(1.3)$ & 11.52 & $<0.01$ & 0.60 & $<0.01^{*}$ & $<0.01^{*}$ \\
\hline Full & $-1.2(1.3)$ & $-0.8(1.0)$ & 12.85 & $<0.01$ & 0.12 & $<0.01^{*}$ & $<0.01 *$ \\
\hline \multicolumn{8}{|c|}{$\begin{array}{l}\text { WAIS-III, Wechsler Adult Intelligence Scale, } 3 r d \text { edn. } \\
\text { a. Online Table DS1 includes this data and the data for first-episode schizophrenia and non-first-episode schizophrenia. Z-scores for controls ( } n=31 \text { ) are mean=0.0 and s.d.=1.0 by } \\
\text { definition. } \\
\text { b. Group numbers: entire first-episode psychosis sample: poor }=78, \text { good }=73 \text {. } \\
\text { c. Global model evaluated with one-way ANOVA: first-episode psychosis d.f.=2. } \\
\text { d. Group differences for entire first-episode psychosis sample evaluated with Bonferroni pair-wise comparisons adjusted for multiple comparisons. } \\
\text { e. Group differences evaluated with Bonferroni } t \text {-tests. } \\
\text { *P significant at } 0.05 \text {. } \\
* * P \text { significant at } 0.008 \text { ( } 0.05 / 6 \text { - corrected for multiple comparisons as per MANOVA design). }\end{array}$} \\
\hline
\end{tabular}


first-episode schizophrenia and non-first-episode schizophrenia patients within the poor-outcome group did not differ on any cognitive domain (all $t$-tests $<0.61$, d.f. $=76$, all $P$ values $>0.55$ ). The same result was found for the good-outcome group $(-1.95<t<0.02$, d.f. $=71$, all $P$ values $>0.06)$ except in reasoning/problem solving where the first-episode schizophrenia results were significantly lower than the non-first-episode schizophrenia patients' results $(t=-2.37$, d.f. $=71, P=0.02)$.

As per IQ, a one-way ANOVA revealed that all three measures significantly varied among the three groups for first-episode schizophrenia and non-first-episode schizophrenia patients. Compared with healthy controls, the poor-outcome groups had significantly lower scores on all IQ measures for both first-episode schizophrenia and non-first-episode schizophrenia patients. In addition, compared with the controls, the first-episode schizophrenia good-outcome group had a lower performance IQ and full-scale IQ score, whereas the non-first-episode schizophrenia good-outcome patients did not differ on any IQ measure. No significant differences were found between poor and good-outcome groups on any IQ measure. The first-episode schizophrenia and non-first-episode schizophrenia patients within the poor-outcome group did not differ on any IQ measure (all $t$-tests $<0.33$, d.f. $=76$, all $P$ values $>0.74$ ). The same result was found for the goodoutcome group (all $t$-tests $>-1.74$, d.f. $=71$, all $P$ values $>0.09$ ) except in performance IQ where the first-episode schizophrenia patients results were significantly lower than the non-first-episode schizophrenia patients' results $(t=-2.18$, d.f. $=71, P=0.03)$.

All of the cognitive domains and IQ measures were independent of (all $\chi^{2}$-tests $>6821.7$, all $P$ values $>0.05$ ) and not correlated with $(-0.19<\rho<0.18$, all $P$ values $>0.05)$ the total positive and negative symptoms at the time of the neuropsychological evaluation. Finally, chi-squared tests revealed no effect of diagnosis on cognitive domains (all $\chi^{2}$-tests $>78.4$, all $P$ values $>0.48$ ). When considering all diagnoses, outcome was independent of diagnosis $\left(\chi^{2}=19.4, P=0.15\right)$; however, when considering first-episode schizophrenia and non-first-episode schizophrenia groupings, outcome was no longer independent of diagnosis $\left(\chi^{2}=8.0, P=0.01\right)$.

\section{Discussion}

\section{Cognitive markers of short-term clinical outcome}

The present study identified deficits in verbal and working memory as markers of poor short-term clinical outcome in individuals with first-episode psychosis evaluated 6 months after admission to a specialised early intervention programme. These findings support prior studies showing cognitive deficits in firstepisode psychosis related to measures of clinical outcome. For example, previous studies have related verbal memory to elevated negative symptoms at $1-3$ years ${ }^{8}$ and to the increased risk of persistent positive symptoms and re-hospitalisation at 2 years. ${ }^{9}$ Also, a general measure of memory has been associated with a poor global symptomatic outcome at 1 year. ${ }^{23}$ These studies, however, used regression analyses to examine the relationship between baseline cognitive levels and symptom ratings at 1 or more years past first admission. Our results, while consistent with the aforementioned studies, provide further evidence that lower levels of performance on verbal and working memories are not only associated with poor outcome but are specific to a subgroup of people with a poorer outcome after 6 months of treatment.

Differences in visual memory, speed of processing, reasoning/ problem-solving and attention did not significantly differentiate between the outcome groups; however, trend level differences were apparent for attention. These results did contrast with previous findings. For example, poor visual memory has been related to poor outcome in the form of persistent psychotic symptoms and more hospitalisations over 2 years, ${ }^{9}$ while speed of processing (Trail Making Test A) and poor executive functioning (Trail Making Test B) have been related to higher negative symptoms over a 3-year period in people with first-episode psychosis ${ }^{8}$ and in individuals with non-remitted schizophrenia. ${ }^{24}$ Although attention was not statistically significant between the outcome groups, the lower attention level in the poor-outcome group supported a previous finding relating poorer attention with a poorer response to treatment after 1 year. ${ }^{25}$ These discrepancies may suggest that visual memory, speed of processing and executive functions are more associated with long-term clinical outcome. In any case, our findings regarding working memory and verbal memory, the same domains reported to be associated with functional outcome and community functioning, ${ }^{7,26}$ support the idea that these specific deficits in cognition are more sensitive than the other cognitive domains to provide an early indication of poor outcome.

Full-scale IQ, as measured by the WAIS-III, was not significantly different between poor-outcome and good-outcome patients. Yet, the poor-outcome group functioned significantly below the good-outcome group on our overall measure of cognitive performance (a score averaged from the six cognitive domains). Because of this apparent inconsistency between the two measures, a general measure of cognitive performance or intelligence may not be a good marker for outcome. Besides, an overall measure of cognition encompasses a wide variety of cognitive functions and not all research studies or treatment facilities use the same cognitive battery. In the end, this would make an overall cognitive measure inconsistent resulting in ambiguous findings or, even worse, false predictions of outcome. Based on our results it appears that using specific cognitive domains may be more sensitive in predicting short-term outcome rather than a global measure of IQ or cognition.

\section{Cognitive heterogeneity}

Our study revealed that all people with first-episode psychosis, independent of diagnosis, functioned lower than healthy controls across all cognitive domains supporting previous results. $3,5,8,9,23,27$ However, we were able to show that within the entire first-episode psychosis sample, working memory and verbal memory were even more compromised in those with a poor outcome compared with those with a good outcome for affective and non-affective psychoses. Although the aforementioned studies have consistently shown global cognitive deficits for all people with first-episode psychosis, ${ }^{3,5,8,9,23,27}$ this could be explained by the fact that single patient groups were compared with either normative values or with values of healthy control groups without considering the heterogeneity of treatment response or outcome. Our results support a previous result ${ }^{28}$ that suggested cognitive heterogeneity is likely present at the onset of illness and in the case of first-episode psychosis could be used as a differential predictor of clinical outcome.

\section{Treatment refractoriness}

The poor-outcome group in our study displayed persistently high negative symptoms over the 6 months that would suggest that these individuals are carrying vulnerabilities that make them less responsive to treatment. As such, could these people be perceived as treatment refractory? Currently, treatment refractoriness is generally conceived of mainly in terms of positive symptoms and not diagnosed until much later in the course of the illness, a time where any changes made in treatment strategies may not 
be effective. In the context of recent interest in an operational definition of remission involving both positive and negative symptoms ${ }^{29}$ and the well-documented association between negative symptoms and functional outcome, ${ }^{30,31}$ including a lack of response on negative symptoms as criterion of treatment resistance may be particularly important. Individuals identified with cognitive deficits in working memory and verbal memory accompanied by a higher level of negative symptoms may be an early identifier of such treatment refractoriness. It is possible, however, that negative symptoms, with a smaller magnitude of change by 6 months, may show further decline in the subsequent months, while positive symptoms generally show most or all of the change within the first 6 months as suggested by a recent Canadian multicentre study of first-episode psychosis. ${ }^{32}$ Further studies are needed to see if there is a link between memory deficits and poor clinical outcome in the form of persistently higher negative symptoms over longer periods. In any case, determining correlates of short-term outcome that can be measured at the beginning of the treatment process may help in better designing treatment strategies and improving expectations with respect to outcome.

\section{Premorbid adjustment and persistent negative symptoms}

The poor-outcome group showed poorer premorbid adjustment in the social domain during childhood and early adolescence compared with the good-outcome group. In addition, as just mentioned, the poor-outcome group displayed significantly higher negative symptoms at the start of the treatment process that persisted at high levels even after 6 months of treatment. Altogether, our results supported previous findings that related poorer premorbid adjustment with higher (persistent) levels of negative symptoms at $1-2$ years past onset. ${ }^{33,34}$ Our results also support, in essence, a second idea that premorbid adjustment is not related to antipsychotic treatment response. ${ }^{25}$ In our sample, both outcome groups showed a reduction in positive symptoms (a response to antipsychotic medications) over the 6 months, albeit a much smaller response was seen in the poor-outcome group. Nevertheless, one could argue that both groups did respond to antipsychotic treatments but at varying levels thus supporting the idea that premorbid adjustment is indeed not related to antipsychotic treatment response. As such, the trend appears to support the idea that poor premorbid levels of adjustment may be more predictive of persistent negative symptoms rather than a response to antipsychotics (a reduction in positive symptoms). At any rate, the possible link between persistent negative symptoms and poor premorbid adjustment should be further examined to provide more evidence and a better understanding.

\section{Strengths}

The strengths of our report include a well-characterised, relatively large sample of people with first-episode psychosis derived from a defined catchment area, the inclusion of in- and out-patients, the exclusion of substance-induced psychosis, the lack or absence of previous treatment and the exposure to specialised treatment over the period of the study from a well-defined service for firstepisode psychosis.

Our study was very representative of young people in the early stages of a first-episode psychosis (mean age $=22.4$ years, s.d=3.9). Among the studies that have examined clinical outcome in firstepisode psychosis, only Addington et $_{\text {al }}^{8}$ studied individuals with similar ages to ours (mean age $=25.5$ years, s.d. $=8.2$ ); the Moritz and Verdoux studies had mean ages of 29.7 years (s.d.=10.1) and 32.1 years (s.d.=10.9), respectively. ${ }^{9,23}$ Also, all other referenced studies used $t$-tests for comparisons among the cognitive variables which do not account for the possible relationships among the dependent variables (cognitive measures) and do not control for Type I errors, while our multivariate analysis did. Additionally, our analysis included a healthy control group that did not differ from the patients in age, gender and socioeconomic status. By using a control group, we controlled for possible demographic differences that may occur with comparisons made to normative data.

The heterogeneity of our sample, with regard to diagnosis at intake, provided a more efficient research design. In fact, outcome studies involving mixed first-episode psychosis samples are being recognised as an efficient research strategy. ${ }^{9}$ This follows from the idea that baseline diagnoses of first-episode patients change rather frequently, ${ }^{35}$ which could lead to erroneously drawing conclusions towards a specific diagnostic category. Among the studies that have examined outcome in first-episode psychosis, the most heterogeneous sample with equal representation of each diagnosis was from Verdoux et al. ${ }^{9}$ On the other hand, Addington et $a l^{8}$ primarily examined first-episode schizophrenia (almost 80\%), while Moritz et al ${ }^{24}$ exclusively examined first-episode schizophrenia. Although our study had a larger proportion of patients with first-episode schizophrenia (73\%) and the first-episode schizophrenia and non-first-episode schizophrenia diagnostic separation was not independent of outcome, this did not affect our overall result. This was supported by the fact that patients with first-episode schizophrenia and non-first-episode schizophrenia had similar cognitive profiles. More importantly, verbal memory and working memory remained significantly compromised in the poor-outcome group compared with the good-outcome group irrespective of diagnosis; moreover, these two cognitive domains were compromised to the same level for each respective outcome group regardless of diagnosis. So, by using a heterogeneous sample that ultimately displayed similar memory deficits throughout, our conclusions are more relevant to all individuals suffering from a first-episode of psychosis and not just to a specific diagnosis within the psychotic disorder spectrum.

The decision to choose a 'remission-like' definition allowed us to examine the patients on an individual symptom basis and observe more closely how they were responding to the specialised treatment programme. We used the same criterion level for the positive symptoms as suggested for remission in schizophrenia ${ }^{29}$ since patients with first-episode psychosis from well-characterised samples show an early and robust response to positive symptoms. ${ }^{32}$ As for the negative symptoms, we chose a higher cut off of mild or less for the following reasons:

(a) the relatively greater interrater error associated with the rating of negative symptoms; ${ }^{36}$

(b) the relatively transient nature of negative symptoms in the majority of people with first-episode psychosis; ${ }^{34}$

(c) the notion of a delayed reduction in negative symptoms in samples of chronic patients ${ }^{37}$ and people with first-episode psychosis. $^{32}$

We also did not include a time period as part of our definition, as suggested for remission, ${ }^{29}$ since we were only examining outcome at 6 months. It must be stressed that we were not trying to assess whether individuals had met the criteria for 'remission' as per the consensus criteria. ${ }^{29}$ Finally, alogia and flat affect have been reported to form a distinct factor within the negative symptom domain ${ }^{38}$ and have been suggested to represent 'core negative' symptoms. Using this concept of core negative symptoms with a rating of moderate or less in our definition, 
the overall results were no different from what we had obtained with our original definition. Although still appealing, these results may be ignoring the practical significance of the other negative symptoms such as anhedonia and avolition in both patients and their families. Moreover, there is no evidence to suggest that the core negative symptoms should only be taken into account when measuring short-term outcome. So, for these reasons, alogia, flat affect, anhedonia and avolition were all included in our definition of outcome.

\section{Limitations}

This study has some limitations. The attention domain was constructed from only one measure of attention (the $\mathrm{d} 2$ concentration performance score). Although this does not satisfy the criteria for a domain, we only had one true measure of attention to use from the standard neuropsychological battery we administer. As such, this measure may not be entirely representative for measuring overall attentional capacities. We also did not include the social cognitive domain when examining the representative domains of dysfunction as outlined by the MATRICS consensus group. ${ }^{17,18}$ On a different note, medication adherence was not confirmed via chemical examination of blood or urine; however, it has been shown that objective information on medication adherence is more reliable than collected samples. ${ }^{39}$ Finally, two individuals with a good outcome and four with a poor outcome refused antipsychotic medications as a treatment option. These people still received psychosocial interventions from the PEPP and, additionally, the removal of these individuals from our sample had no effect on our results.

In summary, cognition is emerging as a reliable marker of early outcome for people diagnosed with psychotic disorders. Cognition has been shown to be compromised across all diagnoses in individuals with first-episode psychosis. ${ }^{4,5,40}$ These deficits are present at the onset of illness ${ }^{27,41}$ stable over time, ${ }^{42,43}$ and independent of initial and changing positive and negative symptoms ${ }^{43}$ and antipsychotic therapy. ${ }^{44}$ In addition, specific cognitive impairments have emerged as a stable marker of both functional ${ }^{6,7}$ and clinical outcomes ${ }^{8,9,23}$ in people with firstepisode psychosis. Our study found specific deficits in verbal memory and working memory in first-episode psychosis to be viable markers of poor outcome after 6 months of treatment. By identifying such individuals early on, clinicians may be encouraged to pay special attention to them in the form of more intensive psychosocial interventions and/or the early introduction of alterative antipsychotics, such as clozapine, which could benefit a proportion of these people.

\footnotetext{
Michael Bodnar, BSC, BA, Brain Imaging Group and Prevention and Early Intervention Program for Psychoses (PEPP-Montreal), Douglas Mental Health University Institute, and Department of Neurology \& Neurosurgery, Montreal University Institute, and Department of Neurology \& Neurosurgery, Montreal
Neurological Institute, McGill University, Montreal, Quebec; Ashok Malla, MD, Ridha Joober, MD, PhD, Brain Imaging Group and Prevention and Early Intervention Program for Psychoses (PEPP-Montreal), Douglas Mental Health University Institute and Department of Psychiatry, Allan Memorial Institute, McGill University, Montreal, Quebec; Martin Lepage, PhD, Brain Imaging Group and Prevention and Early Querc, Martin Lepage, Ph, Brain (PEP Intervention Program for Psychoses (PEPP-Montreal), Douglas Mental Health
University Institute, and Department of Neurology \& Neurosurgery, Montreal University Institute, and Department of Neurology \& Neurosurgery, Montreal
Neurological Institute, and Department of Psychiatry, Allan Memorial Institute, McGil University, Montreal, Quebec, Canada.

Correspondence: Martin Lepage, Douglas Mental Health University Institute, Frank B Common Pavilion, 6875 LaSalle Blvd., Verdun, Montreal, Quebec H4H 1R3, Canada. Email: martin.lepage@mcgill.ca

First received 14 May 2007, final revision 3 Apr, accepted 29 Apr 2008
}

\section{Acknowledgements}

This study was supported by operating grants from CIHR (Number: 68961) and the Sackler Foundation to M.L. and A.M.; M.L. is supported by a salary award from FRSQ; A.M. is supported by the Canada Research Chairs programme. We thank the PEPP-Montreal research staff for their help with recruitment and clinical assessments of participants

\section{References}

1 Menezes NM, Arenovich T, Zipursky RB. A systematic review of longitudinal outcome studies of first-episode psychosis. Psychol Med 2006; 36: 1349-62.

2 Rosen K, Garety P. Predicting recovery from schizophrenia: a retrospective comparison of characteristics at onset of people with single and multiple episodes. Schizophr Bull 2005; 31: 735-50.

3 Addington J, Brooks BL, Addington D. Cognitive functioning in first episode psychosis: initial presentation. Schizophr Res 2003; 62: 59-64.

4 Friis S, Sundet K, Rund BR, Vaglum P, McGlashan TH. Neurocognitive dimensions characterising patients with first-episode psychosis. Br J Psychiatry 2002; 181 (suppl 43): s85-90.

5 Townsend LA, Malla AK, Norman RM. Cognitive functioning in stabilized firstepisode psychosis patients. Psychiatry Res 2001; 104: 119-31.

6 Milev P, Ho BC, Arndt S, Andreasen NC. Predictive values of neurocognition and negative symptoms on functional outcome in schizophrenia: a longitudinal first-episode study with 7-year follow-up. Am J Psychiatry 2005; 162: 495-506

7 Malla AK, Norman RM, Manchanda R, Townsend L. Symptoms, cognition, treatment adherence and functional outcome in first-episode psychosis. Psychol Med 2002; 32: 1109-19.

8 Addington J, Saeedi H, Addington D. The course of cognitive functioning in first episode psychosis: changes over time and impact on outcome. Schizophr Res 2005; 78: 35-43.

9 Verdoux H, Liraud F, Assens F, Abalan F, van Os J. Social and clinical consequences of cognitive deficits in early psychosis: a two-year follow-up study of first-admitted patients. Schizophr Res 2002; 56: 149-59.

10 Malla A, Norman R, McLean T, Scholten D, Townsend L. A Canadian programme for early intervention in non-affective psychotic disorders. Aust N Z J Psychiatry 2003; 37: 407-13.

11 Andreasen NC. Scale for the Assessment of Positive Symptoms (SAPS). University of lowa, 1984.

12 Andreasen NC. Modified Scale for the Assessment of Negative Symptoms (SANS). University of Iowa, 1984.

13 First MB, Spitzer RL, Gibbon M, Williams JBW. Structured Clinical Interview for DSM-IV Axis I Disorders (Patient edn) (SCID-I/P \& SCID-I/NP) (Version 2). New York Psychiatric Institute, Biometrics Research, 1998.

14 Malla A, Norman R, Schmitz N, Manchanda R, Bechard-Evans L, Takhar J, Haricharan R. Predictors of rate and time to remission in first-episode psychosis: a two-year outcome study. Psychol Med 2006; 36: 649-58.

15 Cannon-Spoor HE, Potkin SG, Wyatt RJ. Measurement of premorbid adjustment in chronic schizophrenia. Schizophr Bull 1982; 8: 470-84.

16 Miller DC. Handbook for Research Design and Social Measurement (5th edn). Sage Publications, 1991.

17 Nuechterlein KH, Barch DM, Gold JM, Goldberg TE, Green MF, Heaton RK. Identification of separable cognitive factors in schizophrenia. Schizophr Res 2004; 72: 29-39.

18 Measurement and Treatment Research to Improve Cognition in Schizophrenia (MATRICS). Results of the MATRICS RAND Panel Meeting: Average Medians for the Categories of Each Candidate Test. MATRICS, 2003. (http://www.matrics.ucla.edu/meetings/september-2003/RAND-PanelMedians.pdf).

19 Wechsler D. Weschler Memory Scale (3rd edn). The Psychological Corporation, 1997.

20 Wechsler D. Wecshler Adult Intelligence Scale (3rd edn). The Psychological Corporation, 1997.

21 Reitan RM. Trail Making Test: Manual for Administration and Scoring. Reitan Neuropsychology Laboratory, 1992.

22 Brinkenkamp R, Zillmer E. The d2 Test of Attention. Hogrefe \& Huber Publishers, 1998.

23 Moritz S, Krausz M, Gottwalz E, Lambert M, Perro C, Ganzer S, Naber D. Cognitive dysfunction at baseline predicts symptomatic 1-year outcome in first-episode schizophrenics. Psychopathology 2000; 33: 48-51.

24 Helldin L, Kane JM, Karilampi U, Norlander T, Archer T. Remission and cognitive ability in a cohort of patients with schizophrenia. J Psychiatr Res 2006; 40: 738-45.

25 Robinson DG, Woerner MG, Alvir JM, Geisler S, Koreen A, Sheitman B, Chakos M, Mayerhoff D, Bilder R, Goldman R, Leiberman JA. Predictors of treatment response from a first episode of schizophrenia or schizoaffective disorder. Am J Psychiatry 1999; 156: 544-9. 
26 Green MF. Cognitive impairment and functional outcome in schizophrenia and bipolar disorder. J Clin Psychiatry 2006; 67: e12.

27 Bilder RM, Goldman RS, Robinson D, Reiter G, Bell L, Bates JA, Pappadopulose E, Willson DF, Alvir JM, Woerner MG, Geisler S, Kane JM Lieberman JA. Neuropsychology of first-episode schizophrenia: initial characterization and clinical correlates. Am J Psychiatry 2000; 157: 549-59.

28 Joyce EM, Hutton SB, Mutsatsa SH, Barnes TR. Cognitive heterogeneity in first-episode schizophrenia. Br J Psychiatry 2005; 187: 516-22.

29 Andreasen NC, Carpenter WT, Jr, Kane JM, Lasser RA, Marder SR, Weinberger DR. Remission in schizophrenia: proposed criteria and rationale for consensus. Am J Psychiatry 2005; 162: 441-9.

30 Fenton WS, McGlashan TH. Natural history of schizophrenia subtypes. II. Positive and negative symptoms and long-term course. Arch Gen Psychiatry 1991; 48: 978-86.

31 Keefe RS, Mohs RC, Losonczy MF, Davidson M, Silverman JM, Kendler KS, Horvath TB, Nora R, Davis KL. Characteristics of very poor outcome schizophrenia. Am J Psychiatry 1987; 144: 889-95.

32 Malla A, Schmitz N, Norman R, Archie S, Windell D, Roy P, Zipursky RB. A Multisite Canadian study of outcome of first-episode psychosis treated in publicly funded early intervention services. Can J Psychiatry 2007; 52: 563-71.

33 Addington J, Addington D. Patterns of premorbid functioning in first episode psychosis: relationship to 2-year outcome. Acta Psychiatr Scand 2005; 112 40-6.

34 Malla AK, Norman RM, Takhar J, Manchanda R, Townsend L, Scholten D, Haricharan R. Can patients at risk for persistent negative symptoms be identified during their first episode of psychosis? J Nerv Ment Dis 2004; 192 455-63.

35 Schwartz JE, Fennig S, Tanenberg-Karant M, Carlson G, Craig T, Galambos N Lavelle J, Bromet EJ. Congruence of diagnoses 2 years after a first-admission diagnosis of psychosis. Arch Gen Psychiatry 2000; 57: 593-600.
36 Norman RM, Malla AK, Cortese L, Diaz F. A study of the interrelationship between and comparative interrater reliability of the SAPS, SANS and PANSS. Schizophr Res 1996; 19: 73-85.

37 Szymanski SR, Cannon TD, Gallacher F, Erwin RJ, Gur RE. Course of treatment response in first-episode and chronic schizophrenia. Am J Psychiatry 1996; 153: $519-25$.

38 Malla AK, Takhar JJ, Norman RM, Manchanda R, Cortese L, Haricharan R, Verdi $M$, Ahmed R. Negative symptoms in first episode non-affective psychosis. Acta Psychiatr Scand 2002; 105: 431-9.

39 Fenton WS, Blyler CR, Heinssen RK. Determinants of medication compliance in schizophrenia: empirical and clinical findings. Schizophr Bull 1997; 23: 637-51.

40 Addington J, van Mastrigt S, Addington D. Patterns of premorbid functioning in first-episode psychosis: initial presentation. Schizophr Res 2003; 62: 23-30.

41 Mohamed S, Paulsen JS, O'Leary D, Arndt S, Andreasen N. Generalized cognitive deficits in schizophrenia: a study of first-episode patients. Arch Gen Psychiatry 1999; 56: 749-54.

42 Hoff AL, Sakuma M, Wieneke M, Horon R, Kushner M, DeLisi LE. Longitudinal neuropsychological follow-up study of patients with first-episode schizophrenia. Am J Psychiatry 1999; 156: 1336-41.

43 Nopoulos P, Flashman L, Flaum M, Arndt S, Andreasen N. Stability of cognitive functioning early in the course of schizophrenia. Schizophr Res 1994; 14: 29-37.

44 Brickman AM, Buchsbaum MS, Bloom R, Bokhoven P, Paul-Odouard R, Haznedar MM, Dahlman KL, Hazlett EA, Aronowitz J, Heath D, Shihabuddin L. Neuropsychological functioning in first-break, never-medicated adolescents with psychosis. J Nerv Ment Dis 2004; 192: 615-22. 